\title{
Building A Strong Information And Communication Intervention Strategy For Climate Change In Sub-Saharan Africa
}

\author{
Duruigbo C. I. ' , Nwokeji, E. M. ${ }^{1}$, Peter-Onoh, C. A ${ }^{1}$, Anyaoha, N. ${ }^{2}$, Ogbedeh, \\ K. O. ${ }^{1}$, Ogwudire V. E. ${ }^{1}$, I. I. Ibeawuchi ${ }^{1}$ and Okereke-Ejiogu E.N. ${ }^{2}$ \\ ${ }^{1}$ Department Of Crop Science And Technology, ${ }^{2}$ Department Of Agric. Extension, School of Agriculture and \\ Agricultural Technology, Federal University of Technology P.M. B. 1526, Owerri, Nigeria
}

\begin{abstract}
The adoption of various information and communication intervention measures offers a veritable tool in creating public awareness on climate change in Sub-Saharan Africa which is most vulnerable to the impacts of climate change. Such intervention in climate change information and communication strategy include: use of Research Extension Farmer Information Linkage System (REFILS), which makes use of village extension workers to disseminate climate change information to rural dwellers, use of print and electronic media such as newspapers, magazines, radio and television, encouraging public participation, use of traditional knowledge and information systems, and building a strong environmental information systems, and building a strong environmental information policy on climate change in line with Intergovernmental Panel on Climate Change IPCC) and United Nations Framework Convention on Climate Change (UNFCCC) respectively. The application of these measures and observing good environmental practices as well as sustainable agricultural technologies will reduce climate change induced problems in the sub-region.
\end{abstract}

Keywords: Climate change, information and communication intervention strategy, Sub-Saharan Africa.

\section{Introduction}

Sub-Saharan Africa is a huge and varied continent spanning the tropics, Sub-tropics and warm temperate zones from $37^{0} \mathrm{~N}$ to $35^{\circ} \mathrm{N}$, and is characterized by rapid population growth, low per capita income, low capacity to adapt to climate change due to poverty and existing climate which in many areas is hot and arid (Pittock, 2009).

Africa is one of the most vulnerable continents to climate change and variability, a situation aggravated by the interaction of multiple stresses such as poverty, ecosystem degradation, bad governance, rising sea levels, floods, erosion, HIV/AIDS pandemic human health and food insecurity. The inability of developing countries to respond and act immediately to lessen the impacts of climate change could be attributed firstly due to lack of political will and environmental policies on the part of various governments and the widening information and communication gap existing between environmental scientists, researchers, on one hand and the public sector including farmers on the other hand.

The importance and wisdom of providing the public with full and relevant information thus encouraging public participation is recognized in the RIO Declaration of 1992 which states that environmental issues are best handled with participation of all concerned citizens, at relevant level. At the national level each individual shall have appropriate access to information concerning the environment that is held by public authorities, including information on hazardous materials and activities in their communities and the opportunity to participate in decision-making processes. States shall facilitate and encourage public awareness and participation by making information widely available.

Furthermore, one of the fundamental pre-requisites for the achievement of sustainable development is a broad participation in decision making by all stakeholders in respect of the environment. This includes the need for individual groups and organizations to participate in environmental impact assessment procedures and to know about and participate in decision particularly those which potentially affects the communities in which they live and work (Sharon, 2006). Various international bodies such as United Nations, the Commonwealth Human Rights Initiative all recognize the value of information and communication in sustainable development (CHRI, 2005).

Farmers and non-farming population in rural Sub-Saharan Africa setting are yet to acquire adequate information concerning the direct effects of their activities on climate change, such as crop production, animal husbandry, deforestation, biomass burning, fossil fuel burning and industrial activities. Biomass fuels such as fuel wood, crop residues and animal dung provides about 85-90 percent of domestic energy in rural areas. These anthropogenic activities produce climatically and chemically active atmospheric trace substances and photochemical smog from the combustion of fossil fuels (Andreae, 1991).

This ignorance is highly linked to poverty, education and inability to access relevant climate change information from the media. Public awareness on climate change in Sub-Saharan Africa varies from one country 
to another. Some countries in Sub-Saharan Africa with scientific data on climate change are unable to relate such information in the traditional knowledge setting of the rural population which makes data incompatible and culturally unacceptable in their indigenous mitigation technologies.

There is thus an urgent need to build a strong information and communication strategy that will integrate all stakeholders such as farmers, rural organizations, non-governmental organization, government, religious organizations and policy-makers into a quick intervention response to climate change.

This research paper shall specifically highlight the role of various information and communication strategies in creating awareness to millions of Sub-Saharan Africans being affected by the growing impact as well as the need for policy-driven response on freedom of information on climate change.

\section{Building a Strong Information And Communication Intervention Strategy for Climate Change}

To enhance free flow of information that can easily be adapted and adopted by farmers and other drivers of climate change, the following information and communication strategies will ensure easy diffusion.

\section{Research Extension Farmer Information Linkage System (REFILS)}

In respect of the environment there is need for climatologist and environmental scientist to liaise with agricultural extension workers and make information available to the rural farmers. Such information include; future forecasts on drought, heavy rains, storm etc will guide farmers in adapting to climate change based on the information received from the climatologists via the extension agents. Also farmers problems related to effect of climate change to his crops, livestock and fisheries are sent to the researchers through the extension workers for possible solution. Such a Research Extension and Farmer Information linkage offers a sustainable and strong information diffusion network. Also through this information network people will be properly informed about the environmental compatibility of various agro-chemicals, manufacturing processes, industrial installations and their affects on the environment (Douglas-Scott., 1996). Armed with relevant information people can take informed decisions, take action to protect themselves and avoid activities that encourage greenhouse gas emissions which is instrumental to climate change.

\section{Creating Climate Change Awareness Through the Media}

The mass media namely the television, radio, newspapers, mobile telephones, hand-bills and magazines should be used as a veritable information and communication tool targeted to rural and urban populations in disseminating climate change information. Through various radio and television programmes and information on climate change in Sub-Saharan Africa can be promoted through awareness building and debates, networking and dissemination of research findings, public education and discussions in print and electronic media.

Rural communities in Sub-Saharan Africa differ widely in the types of information they need to enable them adapt to changing climate conditions. There are also considerable differences in the capacity of communication infrastructure and media between countries and rural locations.

\section{Encouraging Public Participation}

African countries should evolve an incentive mechanism to encourage the public and enterprise participation in information diffusion as it affects climate change. This can be encouraged by organizing public debates, discussions and enlightenment campaigns to educate the public on climate change to be initiated by religious leaders, socio-cultural organizations, non-governmental organizations and other climate change interest groups. Other useful audience that should be targeted include, farmers organizations including women groups, project implements, teachers and students, various co-operative societies. These organizations need to be informed properly to enable them play an active role in the adaptation or mitigation of climate change. Information to be disseminate include policy, technical, commercial, market, legal, financial and management aspects of climate change.

Kateere (2000) observed that all stakeholders need to be aware of the various information sources and these include not only technical institutions who are users, providers and managers of information (Brahimi, 2000).

The need for local communities, ministers, research institutions farmers support services, civil society organizations, private companies as wells as international organizations to activity disseminate climate change information is a major step towards creating public awareness required to mobilize action and adaptation measures.

Adequate and accurate information on climate change is critical if the poverty stricken Sub-Saharan Africans are to move forward in livelihood decisions needed to combat poverty in the sub-region.

Public awareness on sustainable life style such as reduce fossil-fuel burning in industries, reduction in deforestation, incorporating climate change publicity and education into the framework of basic education, adult education and higher education, holding various thematic training, seminars, conferences and workshops on 
both popular and professional climate change science, taking full advantage of information technology to enrich the contents and functions of government's climate change information websites and building them up into real, quick response and effective public platform for information dissemination and communication.

There is also need to widen the channels for public participation and supervision, giving full support to the media's supervision and guidance function on public opinion, increasing the transparency of decision making on climate change issue, promoting the science and democracy in the areas of climate change administration while giving support to the initiative of social community organizations and non-governmental organizations (NGOS).

\section{Managing Climate Change Information Using Traditional Knowledge And Information Systems in Sub- Saharan Africa}

The application is traditional knowledge and cultural practices that help reduce greenhouse gas emission has proved to be a veritable tool to disseminate information on climate change. For an effective climate change information, there is need to make such information understandable by using local languages and dialects o communicate. This will help to enhance awareness creating to all rural dwellers both literate and illiterate alike.

Climate change communication and information experts must recognize that family farms, neighbours, colleagues, extended families are characteristics of the farming systems of Sub-Saharan Africa which makes them traditionally communalistic rather than individualistic, hence the relevance of community effort in climate change information and communication intervention strategies. There is need to incorporate culture, religious and social-political values in strategizing climate change information and communication intervention to achieve the desire and positive results.

The history of natural resource management in Sub-Saharan Africa started some two million years ago with human beings tireless pursuit to provide basic food and cultural needs, through hunting and agriculture. Over time humans developed their unique capacity to think, foresee, accumulate and pass on intellectual wealth to subsequent generations (Ewert et al, 2004).

The style, language and dissemination instruments on climate change need to be locally adapted to the various rural communities who are possible users of information on climatic change. A successful factor in climate change communication is to localize a global problem, by creating awareness at local village meeting, cultural dance displays town union meetings market squares and use of cultural artifacts and folks tales to strategize information and communication interventions.

Messages on climate change must rely on clarity and simplicity, to achieve wider coverage, adaptability and implementation. Such messages must be made available free of charge to ensure wider accessibility by majority of rural dwellers in Sub-Saharan Africa who are faced with food insecurity and poverty (Struif-Bontkes and Wolereis, 2003)

Information and communication strategy must be built on local knowledge systems (Nagel, 1980) which metamorphosed into Agricultural Knowledge and Information System (AKIS) foe rural development. This information system links people and institutions to promote mutual learning and generate, share and utilize agricultural related technology, knowledge and information in respect of climate change. The system integrates farmers, agricultural educators and extension agents to harness knowledge and information from various sources for better farming and improved livelihoods (FAO and World Bank, 2000).

Farmers traditional ecological knowledge is historical, cumulative and dynamic, building upon farmers earlier experiences from his ancestors and adapting to the socio-economic changes of the present (Johnson, 1992; Berkes, 1999; Doubleday, 1993; Nakashima, 1993). Any climate change communication intervention strategy build on local knowledge will attract acceptance, and adoptability.

\section{Building A Strong Environmental Information Policy on Climate Change in Sub-Saharan Africa.}

The need for foresight by African leaders is very crucial since this provides the ability to influence the future rather than to predict it. The Inter-governmental Panel on Climate Change (IPCC) was formed to provide foresight in relation to the possible human impacts on climate, with a view to governments formulate wiser, policy options and decisions in relations to climate change, and provide policy-relevant scientific advice.

This followed the call by the general assembly for a United Nations Framework Convention on climate change (UNFCCC) in 1990 which was finally adopted in New York in May 1992 which was opened for signatures of the inter-governmental conference on sustainable development held in RIO de Janeiro in 1992 which have been ratified by 193 countries by 2007. The objective of the UNFCCC include "the stabilization of greenhouse gas concentrations in the atmosphere at the level that would prevent dangerous anthropogenic interference with the climate systems. Such a level should be achieved within a timeframe sufficient to allow ecosystems to adapt naturally to climate change, to ensure that food production is not threatened and to enable economic development proceed in a sustainable manner" 
Sub-Saharan African countries who are most vulnerable to climate change impacts should be in the forefront of articulating an environmentally friendly policy on climate change to conform with the 1997 Kyoto Protocol were various parties to the convention agreed to start the process of reducing greenhouse gases to an average of 5.2\% relative to 1990 emissions to be achieved between 2008-2012. Time has come for various government in Sub-Saharan Africa to confront the challenge of climate change and implement stringent measures to cut greenhouse gas emissions through environmental policies, that will improve lives, sustain the environment and boost food security.

The government awareness in climate change observations and data management will play key roles in disaster management and climate change adaptation and mitigation measures. Such awareness should be championed by African leaders through good governance, proactive research-driven policy and information strategy pursued through country-wide international co-ordination and implementation committees or through such bodes as the African Union (AU) and National Economic Policy on African Development (NEPAD). This will go a long way in spreading information on climate change to all Africans.

A series of policy measures aimed at informing, transforming and tackling the impact of climate change must be part of Sub-Saharan Africa's government development strategy. This will also involve policy oriented information on climate change mitigation and adaptation measures. These should be included in their various development plants.

African leaders should also embark on policy measures that encourage tree planting and discourage deforestation, reduce the burning of fuels in automobiles and avoid unsustainable agricultural practices that cause environmental pollution and degradation. Governments in Sub-Saharan Africa must make budgetary allocations for ecological management and encourage public education at all levels to create awareness on climate change. The policy option must be designed to include the establishment of Geographic Information Systems (EWS) mounted at strategic locations to track down climate change related data for onward use in mitigation and adaptation to climate change.

The poor communication and information infrastructure in most African countries does not augur well to make any meaningful climate change impact due to poor information services. The adoption of the latest Information and Communication Technologies (ICTS) in climate change policies must be embraced by all governments to speed up awareness on climate change, such information and communication technology tools should be made readily available, cheap and easy to access. Example, the use of mobile phones for information dissemination is increasing in Sub-Saharan Africa possibly due to its relatively inexpensive cost and ease of operation even with illiterate faming and non-farming populations.

Also the use of internet can be a good information and communication and communication tool to boost climate change awareness to all Africans, as long as government policy favours easy and low cost acquisition of such communication tools.

It is now crucial to institute a legal framework to back freedom of information especially as it concerns climate change to strengthen, publicize and induce people to adapt and mitigate climate change in the sub-region. Government should encourage all media practitioners to embrace local language and methods of information dissemination in climate change communication to ensure easy adaptation and implementation by the various individuals. This can be enforced through good policies, legislation and projects that create awareness, participation and implementation of relevant climate change information in various African countries.

\section{Conclusion}

Sub-Saharan Africa is one of the most vulnerable continents suffering from the impact of climate change which further aggravated its problem of food insecurity, poverty, disease, environmental degradation, and drought and climate-change conflicts. The adoption of a strong information and communication intervention strategy by various stakeholders will boost the campaign on climate change and create both public and private awareness on mitigation and adaptation measures needed to tackle, challenge, including information policy options.

\section{References}

[1] Andreae, M.O. 1991 "Biomass burning in the tropics" Impact on environmental quality and global climate In: K. Davis and M.S. Bernstam (eds). Resources, environmental and population: Present knowledge, future options pp 268-291. New York. Oxford University Press.

[2] Berkes F. 1999. Sacred Ecology. Traditional Ecological Knowledge and Resources Management, Philadelphia, P.A Taylor and France (ed) In: in the way of development, edited by Mario Blaser, Harvey A feit and Glenn Mcraen pp. $72-87$.

[3] Brahimi, Y. 2000. Monitoring, evaluation and exchanging information and desertification: The Implementation on the CCD in Africa. In proceedings of a CTA Workshop on Information support for natural resource management policy, Wageningen, the Netherlands, 26-29 January 1991. Pp.99-110.

[4] CHRI (Common Wealth Human Rights Initiative,) 2005. Draft principles on Human Rights and the environment 350pp. 
[5] Doubleday, N. 1993. "Finding common ground, natural law and collective wisdom" In: J. Inglis (ed), Traditional Ecological knowledge; concepts and cases Ottawa On: International Program Traditional Ecological knowledge and International Development Research Centre, pp. 41-53.

[6] Douglas-Scott, S. 1996 Environmental Rights in the European Union; participatory democracy or democratic deficit? In A.E. Boyle \& M.R. Anderson (eds). Human rights Approaches to Environmental Protection. Clarendon Press Oxford pp. 109-28.

[7] Ewert, A.W., Baker, D.C. and Bissix G.C. 2004. Integrated Resources and Environmental Management: The Human Dimension. CABI Publishing. Wallingford. $290 \mathrm{pp}$.

[8] FAO (Food and Agriculture Organization) And World Bank 2000. Agricultural knowledge and Information Systems for Rural Development (AKISFD) strategic vision and guiding principles: FAO Rome and World Bank. Washington.

[9] Johnson, M. 1992. Lore: capturing Traditional Environmental knowledge, Ottawa, On: Dene Culture Institute and the International Development Research Centre. In: The way of Development, Mario Bleser, Harvey A Feit and Glenn Mcrae (eds) pp. 78-88.

[10] Karterere, Y. 2000. Who makes policy and hoe? The case of community based natural resources management in Southern Africa. In: proceedings of a CTA workshop on information support for natural resources management policy. Wageningen, The Netherlands, 26 -29 January 1999. Pp. $31-52$.

[11] Nagel, U.J. 1980. Institutionalization of knowledge flows; an analysis of the extension role of two Agriculture Universities in India. Special issue of the Quarterly Journal of International Agriculture. 30 DLG Verlag Frankfurt.

[12] Nakashima, D. 1993. "Astute observer on the sea ice edge: Imut knowledge as a basis for Arctic co-management “ In: J. Inglis (ed), Traditional Ecological knowledge: Concepts and cases, Ohawa On: International Development Research Centre Pp. 99 - 100.

[13] Pittock, A.B. 2009. Climate Change: The science, Impacts and Solution CSIRO publishing, Australia 350 Pp.

[14] Sharon Beder 2006. Environmental Principle and Policies: An Interdisciplinary Introduction. Earthscan Publishers London. 304 pp.

[15] Struif Bontkes, T.E. and M.C.S. Woperies tools for small holder agriculture in Sub-Saharan 2003. Opportunities for the use of decision support Africa. In: struiff Bonks, T.E. and M.C.S. Wopereis (eds). Decision support tools for small holder agriculture in Sub-Saharan Africa. A practical guide. CTA. The Netherlands 123pp. 